\title{
Determination of comfort indices of fabrics using fabric touch tester (FTT)
}

Cite as: AIP Conference Proceedings 2368, 020005 (2021); https://doi.org/10.1063/5.0057777 Published Online: 29 June 2021

Atiyyah binti Haji Musa, Benny Malengier, Simona Vasile, and Lieva Van Langenhove

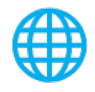

\section{ARTICLES YOU MAY BE INTERESTED IN}

Effect of applied potential on the morphological and structural properties of ZnO nanostructures

AIP Conference Proceedings 2368, 020002 (2021); https://doi.org/10.1063/5.0058188

Detection of low PPM of volatile organic compounds using nanomaterial functionalized reduced graphene oxide sensor

AIP Conference Proceedings 2368, 020004 (2021); https://doi.org/10.1063/5.0057775

Preface: Physics and Materials Science International Symposium 2021 (PhyMaS 2.0) AIP Conference Proceedings 2368, 010001 (2021); https://doi.org/10.1063/12.0005216

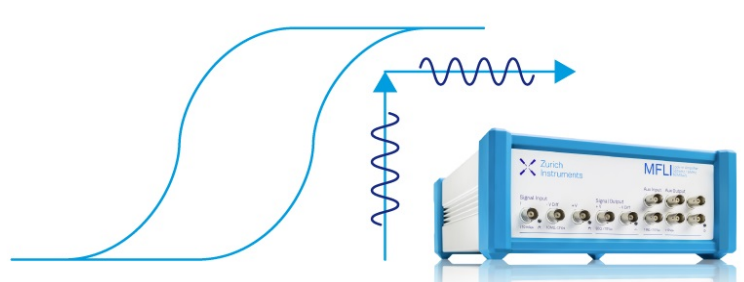

Webinar

How to Characterize Magnetic Materials Using Lock-in Amplifiers

Zurich

Instruments

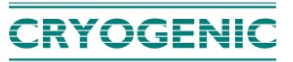




\title{
Determination of Comfort Indices of Fabrics Using Fabric Touch Tester (FTT)
}

\author{
Atiyyah binti Haji Musa, a), Benny Malengier ${ }^{2, \text { b) }}$, Simona Vasile ${ }^{3, c)}$ and Lieva Van \\ Langenhove ${ }^{2, \text { d) }}$
}

\begin{abstract}
${ }^{I}$ Universiti Teknologi MARA Cawangan Negeri Sembilan, Kampus Kuala Pilah, Negeri Sembilan, Malaysia. ${ }^{2}$ Ghent University, Faculty of Engineering and Architecture, Department of Materials, Textiles and Chemical Engineering, Centre for Textile Science and Engineering, Belgium.

${ }^{3}$ University College Ghent, Faculty of Science and Technology, Department of Textiles, Fashion and Wood Technology, Belgium.
\end{abstract}

a) Corresponding author: atiyyah@uitm.edu.my

b) Benny.Malengier@UGent.be

c)Simona.Vasile@HoGent.be

d)Lieva.VanLangenhove@UGent.be

\begin{abstract}
Being comfortable with the fabrics that we are wearing is one of the elements of satisfaction in life. Hence, fabric comfort needs to be quantified in order to understand the factors that make it comfortable. However, the evaluation of comfort is often related to ambiguity and subjectivity which hinder the potential to be applied widely in the clothing industry. Therefore, this study aims to measure comfort indices of fabric by incorporating the use of a relatively new equipment in the market; Fabric Touch Tester (FTT). The performance of FTT in discriminating the hand of polyestercotton knitted fabrics made of airjet, rotor, compact and ring-spun yarns with two levels of twist was analysed. The results indicate that the FTT device can successfully distinguish between the considered fabrics. From the generated models, the FTT indices and input variable relationship were obtained with $0.4-0.6 \mathrm{R}^{2}$ value. The type of yarn has an obvious influence on fabric thermal conductivity while the levels of yarn twist considered moderately affected the compression recovery and surface friction properties of the fabrics. Based on the measured fabric indices, FTT also made predictions on comfort indices of the fabrics which shows low twisted compact yarns are the roughest with the lowest index 0.02 while airjetbased fabrics are the smoothest but hardest i.e. index 0.28 and 0.61 respectively. In comparison with other tested fabrics, ring-based fabrics are the softest; i.e. index 0.7 . This suggests the feasibility of the instrument for tactile measurement of fabrics. However, the precision of the comfort prediction models of FTT needs to be validated by human panels or different measuring methods.
\end{abstract}

\section{INTRODUCTION}

Fabric hand or handle is always a general concern to the end users when purchasing fabrics and most importantly for the fabric manufacturers that have to provide fabrics to suit the needs and expectations of the users. New fibers, fabric treatments or yarn types were investigated [1]-[4] aiming at a better hand of the fabrics for clothing. The handle of fabric is quantified by touching it. As touch is characterized by the fabric being in contact with the skin, fabric handle is a subjective evaluation which greatly depends on the sensitivity of humans' touch senses and their preferences. Therefore, since many decades, scientists have been trying to quantify this property indirectly by employing some devices which objectively measure several touch-related fabric physical properties such as bending, surface friction and roughness. The measured fabric properties were then correlated to the comfort perception of humans such as smoothness, softness and warmth [5]-[7]. The two most established comfort evaluation systems in use are Kawabata Evaluation System (KES) [8], [9] and Fabric Assurance by Simple Testing (FAST) [10]. Also,

Proceedings of the 2nd Physics and Materials Science International Symposium (PhyMaS 2.0)

AIP Conf. Proc. 2368, 020005-1-020005-8; https://doi.org/10.1063/5.0057777

Published by AIP Publishing. 978-0-7354-4106-4/\$30.00 
Tissue Softness Analyzer (TSA) which is initially developed for the paper sector, claims to be suitable for quantification of softness and smoothness of textile materials [11].

Fabric Touch Tester (FTT) device was relatively recently manufactured for the same purpose of fabric hand assessment. Unlike other devices, FTT comprises four modules (i.e., compression, bending, thermal and surface module) within a single instrument and it simultaneously assesses 13 fabric physical indices in less than five minutes, in bi-direction, both face and back sides of the fabric. Subsequently, three primary comfort indices (i.e., smoothness, softness, and warmth) and two global comfort indices (i.e., total hand and total touch) are predicted by the built-in statistical models based on the neuro-physiological stimulus mechanism of fabric touch feeling. These models are computed from the correlations between FTT-measured fabric properties and scores given by panel members to softness, smoothness, and warmth of a specific set of clothing fabrics. These models are undisclosed by the manufacturer. Details about the modules of the instrument and calculation of the indices have been reported elsewhere [12]-[14]. This instrument has been already employed to study variation of fabric hand with various production settings, fiber type and fabric treatments among others [15]. It seems also to be sensitive enough to discriminate between fabrics for protective clothing with comparable mass per surface area or thickness [16]. Moreover, the device could successfully distinguish between tactile properties of cellulosic (e.g. Tencel ${ }^{\circledR}$, Modal, etc.) fabrics and the predicted FTT comfort indices (e.g. softness, smoothness) were in good agreements with the human panel and TSA device [11]. Reliability of the device thickness and bending measurement was also analyzed in comparison with the standard method [17] and a recent study [18] described the ability of the FTT to discriminate between FTT primary comfort indices of knitted fabrics differentiated by two finishing treatments. The same study [18] also compared two types of yarns (i.e., ring-spun and air-jet yarns) but do not report on correlations between FTT comfort indices and human assessment. Other researchers have used other instruments such as KES or human panel in similar studies about fabric handle [19]-[21].

To the best of the authors' knowledge, no published study investigated the capability of the FTT to differentiate between knitted fabrics made of different types of spun yarns with different levels of twist. Hence, in this study, the ability of FTT to distinguish between fabrics differentiated by four types of yarns from different spinning systems and two twist levels will be analysed.

\section{MATERIALS AND METHODS}

Four types of blended yarn ( $60 \%$ cotton and $40 \%$ polyester) Ne 20 were produced via airjet, rotor, compact and ring spinning method with two levels of twist i.e., 800 and 900 twist/meter. The yarns were subsequently used to produce eight knitted fabrics $\left(128-135 \mathrm{~g} / \mathrm{m}^{2}\right)$ with a similar single jersey structure (see FIGURE 1) and a fabric density of 9 wales $/ \mathrm{cm}$ and 27 courses $/ \mathrm{cm}$ respectively. Prior to testing, all fabrics were placed for at least 24 hours in a conditioning room, controlled at $21^{\circ} \mathrm{C} \pm 2{ }^{\circ} \mathrm{C}$ and relative humidity of $65 \% \pm 4 \%$ [22]. Both fabric hand assessment by FTT and human panels were performed in the same climate room. The fabrics are denoted with their yarn spinning systems followed by the letters HT or LT where HT refers to high twist value (i.e., 900 twist/meter) and LT to low twist (i.e., 800 twist/meter).
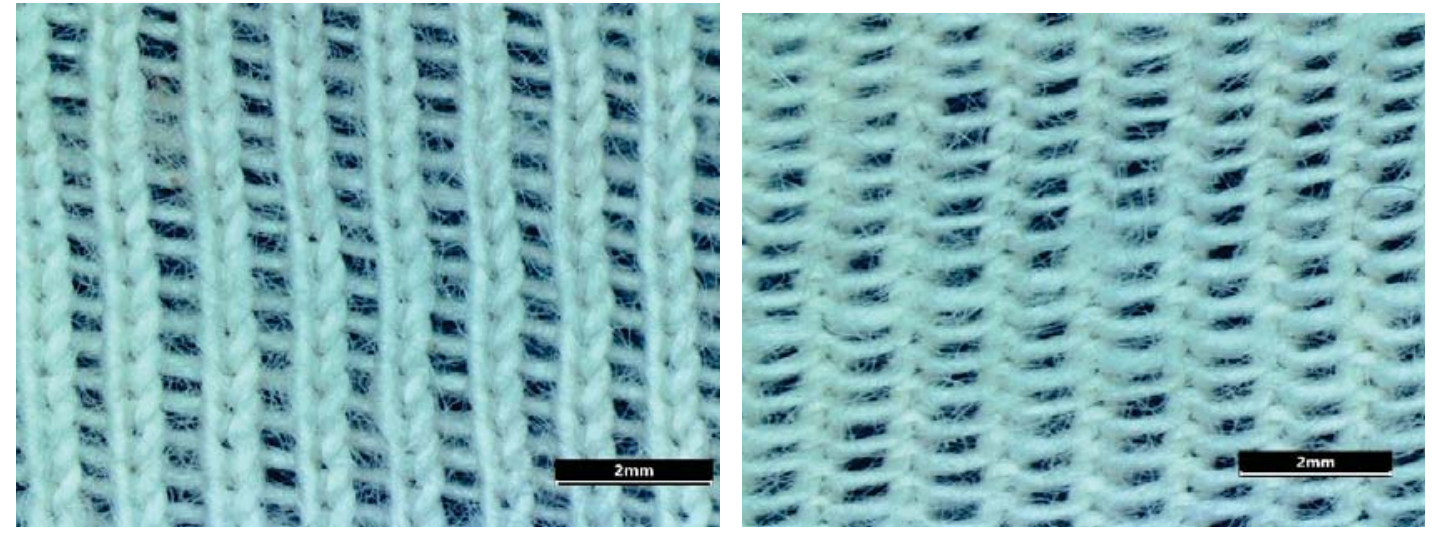

FIGURE 1. Knitted structure of the fabrics; left- outside/ technical face, right- inside/ technical back. 


\section{Assessment of Fabric Hand by FTT Device}

All eight fabrics ( 4 spinning methods $\mathrm{x} 2$ twist levels) were tested by the FTT. Each fabric was cut in an L shape as per guidelines provided by the machine manufacturer [14]. The sample was placed on the bottom plate of the FTT instrument with the two legs of the $\mathrm{L}$ shape positioned on adjacent platforms within the device. Prior to testing, the upper plate was controlled at $10^{\circ} \mathrm{C}$ higher than the bottom plate to mimic the temperature difference between skin and textiles. When the test starts, the upper plate moves gradually downward and touches the fabric on the bottom plate. The fabric is brought further downward by both plates and in several seconds, it reached the lowest position after which it went back to the initial position. During the upward and downward movement, the fabric compression, bending, thermal and surface properties (i.e., friction and roughness) are measured. The measured properties yield 13 different FTT fabric indices and next, the primary (i.e., smoothness, softness, warmth) as well as the global comfort indices (i.e., total hand and total touch) are computed by the FTT software which are linear combinations of the FTT fabric indices [23]. For each fabric, 20 specimens were tested, 10 for outside and also another 10 for inside and in both fabric wale (a) and course (e) direction. The 13 indices measured by FTT are listed in TABLE 1 which also contains their interpretation as well as the FTT and SI measurement units respectively. No standard yet exists, hence the test is done by following the guidelines provided by the manufacturer [14] and other recommendations and good practices [24].

TABLE 1. Interpretation of the FTT fabric indices.

\begin{tabular}{|c|c|c|c|c|c|c|}
\hline Item & $\begin{array}{l}\text { Fabric } \\
\text { Property }\end{array}$ & Index & Description & $\begin{array}{l}\text { Unit } \text { given } \\
\text { by FTT } \\
\text { software }\end{array}$ & SI unit & Usual interpretations \\
\hline 1 & Bending & BAR & $\begin{array}{l}\text { Bending Average } \\
\text { Rigidity }\end{array}$ & gf $\mathrm{mm} \mathrm{rad}^{-1}$ & $\mathrm{~N} \mathrm{~m} \mathrm{rad}-1$ & $\begin{array}{l}\text { Force needed to bend per } \\
\text { radian }\end{array}$ \\
\hline 2 & & BW & Bending Work & gf $\mathrm{mm}$ rad & $\mathrm{N} \mathrm{m} \mathrm{rad}$ & Work needed to bend \\
\hline 3 & $\begin{array}{l}\text { Surface } \\
\text { friction }\end{array}$ & SFC & $\begin{array}{l}\text { Surface Friction } \\
\text { Coefficient }\end{array}$ & & - & $\begin{array}{l}\text { Friction coefficient on } \\
\text { surface with ribbed plate }\end{array}$ \\
\hline 4 & $\begin{array}{l}\text { Surface } \\
\text { roughness }\end{array}$ & SRA & $\begin{array}{l}\text { Surface Rough- } \\
\text { ness Amplitude }\end{array}$ & $\mu \mathrm{m}$ & $\mathrm{m}$ & $\begin{array}{l}\text { Roughness irregular wave } \\
\text { amplitude }\end{array}$ \\
\hline 5 & & SRW & $\begin{array}{l}\text { Surface Rough- } \\
\text { ness Wavelength }\end{array}$ & $\mathrm{mm}$ & $\mathrm{m}$ & $\begin{array}{c}\text { Roughness irregular wave } \\
\text { wavelength }\end{array}$ \\
\hline 6 & Compression & $\mathrm{CW}$ & $\begin{array}{l}\text { Compression } \\
\text { Work }\end{array}$ & gf mm & $\mathrm{N} \mathrm{m}$ & $\begin{array}{l}\text { Work needed to compress } \\
\text { the specimen }\end{array}$ \\
\hline 7 & & CRR & $\begin{array}{l}\text { Compression } \\
\text { Recovery Rate }\end{array}$ & - & - & $\begin{array}{l}\text { Percentage of thickness } \\
\text { changes after compressed }\end{array}$ \\
\hline 8 & & CAR & $\begin{array}{l}\text { Compression } \\
\text { Average Rigidity }\end{array}$ & $\mathrm{gf} \mathrm{mm}^{-3}$ & $\mathrm{~N} \mathrm{~m}^{-3}$ & $\begin{array}{l}\text { Forces needed to } \\
\text { compress per } \mathrm{mm}\end{array}$ \\
\hline 9 & & RAR & $\begin{array}{l}\text { Recovery } \\
\text { Average Rigidity }\end{array}$ & $\mathrm{gf} \mathrm{mm}^{-3}$ & $\mathrm{~N} \mathrm{~m}^{-3}$ & $\begin{array}{l}\text { Forces reflected when } \\
\text { recovery per mm }\end{array}$ \\
\hline 10 & & $\mathrm{~T}$ & Thickness & $\mathrm{mm}$ & & Thickness of the materials \\
\hline 11 & $\begin{array}{l}\text { Thermal } \\
\text { conductivity }\end{array}$ & TCC & $\begin{array}{l}\text { Thermal } \\
\text { Conductivity } \\
\text { under } \\
\text { Compression }\end{array}$ & $\begin{array}{l}10^{-3} \mathrm{~W} \mathrm{~m}^{-1} \\
{ }^{\circ} \mathrm{C}^{-1}\end{array}$ & $\mathrm{~W} \mathrm{~m}^{-1}{ }^{\circ} \mathrm{C}^{-1}$ & $\begin{array}{l}\text { Energy transmitted per } \\
\text { degree per m per second } \\
\text { under specimen } \\
\text { compression }\end{array}$ \\
\hline 12 & & TCR & $\begin{array}{l}\text { Thermal } \\
\text { Conductivity } \\
\text { under Recovery }\end{array}$ & $\begin{array}{l}{ }^{10^{-3}} \mathrm{~W} \mathrm{~m}^{-1} \\
{ }^{\circ} \mathrm{C}^{-1}\end{array}$ & $\mathrm{~W} \mathrm{~m} \mathrm{~m}^{-1}{ }^{\circ} \mathrm{C}^{-1}$ & $\begin{array}{l}\text { Energy transmitted per } \\
\text { degree per m per second } \\
\text { under specimen recovery }\end{array}$ \\
\hline 13 & & Qmax & $\begin{array}{l}\text { Thermal } \\
\text { Maximum Flux }\end{array}$ & $\mathrm{W} \mathrm{mm^{-2 }}$ & $\mathrm{W} \mathrm{m}^{-2}$ & $\begin{array}{l}\text { Maximum energy trans- } \\
\text { mitted during compression }\end{array}$ \\
\hline
\end{tabular}

The FTT algorithm first computes the measured 13 fabric indices and then predicts three primary comfort indices: smoothness, softness and warmth. The FTT also distinguishes between active and passive for these primary comfort indices which are calculated for the outside (technical face) and inside (technical back) of the fabrics, respectively. 
Active comfort indices resemble the conscious evaluation made with fingers. On the contrary, passive indicates the feeling of the wearer when wearing the fabrics. In this study, only the outside of the fabrics were considered for active smoothness and softness comfort indices which can have values between 0 and 1 . A value 0 indicates the roughest or hardest fabric and 1 indicates the smoothest and softest, based on the predictive models computed by the FTT software.

\section{RESULTS AND DISCUSSION}

In this section, the results from FTT are reported and discussed. For FTT, the variation of the 13 fabric indices is presented, as well as some statistical analysis implemented to obtain the influence of the parameters towards the indices. Furthermore, the statistical models which describe the dependency of FTT fabric indices on yarn type and twist are explained.

\section{Variation of FTT Fabric Indices with Yarn Spinning Method and Twist}

Each of the fabrics was tested with the FTT and the results for the FTT fabric indices are given in Table 2. The results for the 13 fabric indices are described with the mean and standard deviation (SD) for each fabric. As can be seen in TABLE 2, bending work (BW) of the fabrics with compact yarns is the highest compared to the other types of yarn and low twisted yarns always have led to fabrics with high bending average rigidity (BARa). Relatively high standard deviation (SD) of some FTT fabric indices (i.e., roughness and friction) may be partially related to the fabric itself as it is thin and rolled up at the edges (see FIGURE 2) with difficulties in correct positioning of the specimen within the instrument as a consequence. Roughness and friction are measured at the legs of the L-shaped sample which were sometimes rolled up and not correctly touching the roughness sensor, therefore large variation or some errors sometimes occurred. This was not the case for thermal and compression properties, in which case the measurement was taken at the middle part of the fabric. Hence, correct values of thermal, bending and compression indices were expected but friction coefficient (SFC) and roughness properties (SRA, SRW) could be prone to some errors, in both course and wale direction, which was also reported elsewhere [24]. Nevertheless, during analysis, errors in the measurements were replaced by NaN (not a number or unpresentable values) and these were not included in the data analysis, apart from reducing the number of valid measurements. The dataset was tested for outliers and these were also removed, hence only the values within the interquartile range (IQR) were retained to create the comfort models. The outliers indicate a glitch in the experimental set-up in which the value is far from the valid range for the fabric of the same type. However, no clear trend or influence of type of spinning and twist levels on the FTT fabric indices could be directly seen, hence further analysis of the data is required.

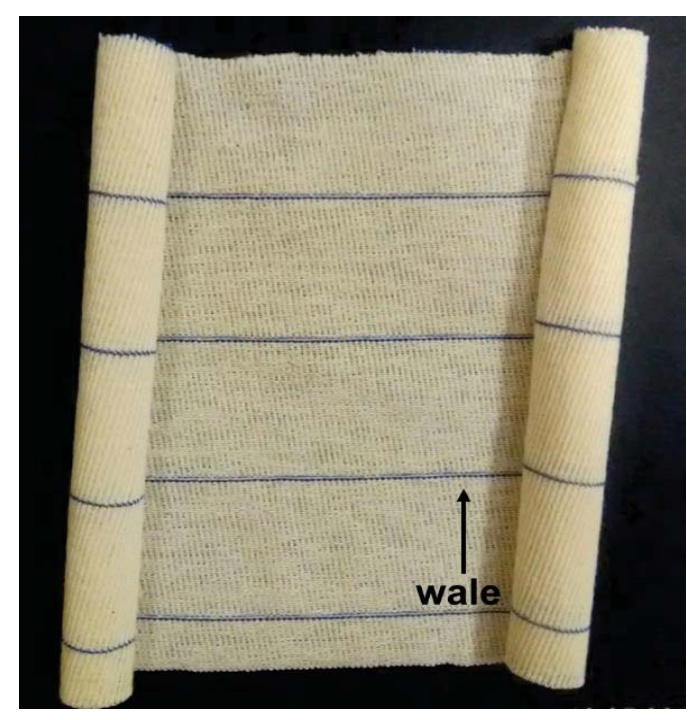

FIGURE 2. Inside/ technical back of a fabric with rolled-up edges. 
TABLE 2. Means and standard deviations (SD) of FTT fabric indices for the outsides of the eight fabrics, in wale (a) and course (e) direction.

\begin{tabular}{|c|c|c|c|c|c|c|c|c|c|}
\hline & \multicolumn{8}{|c|}{ Fabric Types } \\
\hline & & $\begin{array}{l}\text { Airjet } \\
\text { HT }\end{array}$ & $\begin{array}{l}\text { Airjet } \\
\text { LT }\end{array}$ & $\begin{array}{l}\text { Rotor } \\
\text { HT }\end{array}$ & $\begin{array}{l}\text { Rotor } \\
\text { LT }\end{array}$ & $\begin{array}{l}\text { Compact } \\
\text { HT }\end{array}$ & $\begin{array}{l}\text { Compact } \\
\text { LT }\end{array}$ & $\begin{array}{l}\text { Ring } \\
\text { HT }\end{array}$ & $\begin{array}{l}\text { Ring } \\
\text { LT }\end{array}$ \\
\hline \multirow[t]{2}{*}{ *BARa } & Mean & 268.55 & 305.79 & 260.81 & 372.57 & 296.59 & 384.52 & 305.05 & 321.55 \\
\hline & SD & 40.51 & 74.28 & 44.23 & 164.47 & 114.11 & 91.67 & 60.95 & 86.16 \\
\hline \multirow[t]{2}{*}{ *BARe } & Mean & 77.04 & 67.15 & 87.23 & 61.18 & 80.87 & 82.52 & 74.00 & 73.62 \\
\hline & SD & 16.04 & 31.42 & 10.73 & 28.48 & 20.56 & 34.08 & 32.71 & 24.13 \\
\hline \multirow[t]{2}{*}{$* \mathrm{BWa}$} & Mean & 747.65 & 835.51 & 841.06 & 887.57 & 892.43 & 1103.96 & 936.34 & 968.16 \\
\hline & $\mathrm{SD}$ & 135.85 & 131.42 & 107.46 & 176.63 & 274.34 & 177.13 & 58.18 & 192.02 \\
\hline \multirow[t]{2}{*}{$* \mathrm{BWe}$} & Mean & 380.80 & 339.74 & 360.91 & 266.22 & 356.94 & 336.28 & 367.97 & 324.20 \\
\hline & SD & 16.79 & 101.84 & 16.03 & 104.25 & 33.19 & 63.40 & 53.01 & 46.30 \\
\hline \multirow[t]{2}{*}{$\mathrm{CW}$} & Mean & 1954.98 & 2053.96 & 2216.10 & 2329.78 & 2271.21 & 2279.42 & 2424.60 & 2469.49 \\
\hline & SD & 235.12 & 288.66 & 170.48 & 88.44 & 81.40 & 164.88 & 164.59 & 132.91 \\
\hline \multirow[t]{2}{*}{ CRR } & Mean & 0.40 & 0.42 & 0.39 & 0.39 & 0.40 & 0.38 & 0.42 & 0.39 \\
\hline & $\mathrm{SD}$ & 0.04 & 0.02 & 0.04 & 0.04 & 0.01 & 0.02 & 0.01 & 0.02 \\
\hline \multirow[t]{2}{*}{ CAR } & Mean & 116.02 & 110.92 & 109.78 & 106.74 & 109.35 & 115.17 & 105.20 & 103.43 \\
\hline & SD & 10.12 & 8.73 & 9.84 & 6.94 & 7.15 & 12.09 & 4.48 & 7.45 \\
\hline \multirow[t]{2}{*}{ RAR } & Mean & 355.86 & 313.32 & 296.48 & 282.80 & 287.37 & 275.43 & 257.46 & 267.65 \\
\hline & SD & 52.66 & 38.27 & 22.05 & 13.25 & 31.63 & 18.98 & 25.89 & 24.30 \\
\hline \multirow[t]{2}{*}{$\mathrm{T}$} & Mean & 1.11 & 1.23 & 1.48 & 1.49 & 1.61 & 1.74 & 1.55 & 1.59 \\
\hline & SD & 0.10 & 0.20 & 0.21 & 0.13 & 0.22 & 0.13 & 0.16 & 0.20 \\
\hline \multirow[t]{2}{*}{ TCC } & Mean & 63.19 & 64.60 & 68.62 & 68.45 & 71.48 & 72.62 & 72.70 & 71.92 \\
\hline & SD & 3.53 & 3.33 & 3.09 & 2.21 & 2.04 & 2.04 & 1.18 & 1.83 \\
\hline \multirow[t]{2}{*}{ TCR } & Mean & 61.96 & 63.54 & 67.57 & 66.92 & 70.98 & 72.36 & 70.48 & 71.05 \\
\hline & SD & 3.55 & 3.45 & 3.24 & 2.03 & 2.96 & 1.90 & 2.09 & 2.44 \\
\hline \multirow[t]{2}{*}{ Qmax } & Mean & 623.58 & 595.67 & 522.72 & 517.04 & 504.89 & 465.97 & 525.72 & 514.87 \\
\hline & SD & 34.83 & 64.95 & 54.24 & 35.22 & 61.29 & 30.21 & 38.63 & 54.05 \\
\hline \multirow[t]{2}{*}{ *SFCa } & Mean & 0.46 & 0.44 & 0.47 & 0.46 & 0.47 & 0.46 & 0.48 & 0.47 \\
\hline & SD & 0.02 & 0.01 & 0.01 & 0.01 & 0.01 & 0.01 & 0.01 & 0.01 \\
\hline \multirow[t]{2}{*}{ *SFCe } & Mean & 0.48 & 0.61 & 0.53 & 0.51 & 0.58 & 0.57 & 0.56 & 0.58 \\
\hline & SD & 0.03 & 0.13 & 0.07 & 0.06 & 0.13 & 0.12 & 0.11 & 0.13 \\
\hline \multirow[t]{2}{*}{ *SRAa } & Mean & 161.88 & 150.54 & 99.41 & 93.60 & 62.03 & $* * 0.00$ & 24.16 & 39.67 \\
\hline & SD & 59.98 & 48.58 & 48.64 & 63.21 & 59.94 & $* * 0.00$ & 39.66 & 58.21 \\
\hline \multirow[t]{2}{*}{ *SRAe } & Mean & 210.47 & 195.10 & 178.44 & 185.65 & 170.82 & 191.89 & 177.06 & 168.51 \\
\hline & SD & 28.52 & 27.39 & 14.02 & 34.77 & 21.49 & 59.68 & 43.08 & 22.89 \\
\hline \multirow[t]{2}{*}{ *SRWa } & Mean & 4.52 & 5.29 & 4.66 & 3.79 & 2.92 & $* * 0.00$ & 0.38 & 1.03 \\
\hline & SD & 1.12 & 1.46 & 2.88 & 2.60 & 3.21 & $* * 0.00$ & 1.06 & 1.58 \\
\hline \multirow[t]{2}{*}{ *SRWe } & Mean & 1.16 & 1.16 & 1.16 & 1.17 & 1.21 & 1.20 & 1.19 & 1.16 \\
\hline & SD & 0.03 & 0.04 & 0.03 & 0.04 & 0.01 & 0.09 & 0.07 & 0.04 \\
\hline
\end{tabular}

*Small letters following the indices indicates: a- wale direction; e- course direction; $\mathrm{m}$ - average value in wale and course directions.

**These values are calculated by the FTT when the fabric is moving through the roughness sensor for $5 \mathrm{~cm}$. When the FTT algorithm cannot compute the value, it assumes 0 , which is an erroneous value not used in our analysis.

The variation of FTT fabric indices with yarns spinning method and twist was investigated through the generation of statistical models from the complete dataset. The models are established using python Statsmodel package. The yarn type (i.e., ring-spun, compact, airjet and rotor) is treated as a categorical item with two levels $(0,1)$. Stepwise regression is used, considering only linear terms with $\mathrm{p}<0.05$ for the coefficients, which shows the relevance of the respective coefficient of the model. The sign of the coefficients of the statistical models indicates a strong positive $(+)$ or negative (-) influence of the respective variable on FTT fabric indices considered and high $\mathrm{R}^{2}$ values (i.e., above 0.8 ) indicate a strong FTT indices-input variable relationship. Almost all models obtained have moderate $\mathrm{R}^{2}$ which are around $0.4-0.6$, as shown in TABLE 3 . If the mean values are used in the model, the $\mathrm{R}^{2}$ would considerably increase at approximately 0.4 higher than the models with the complete dataset. This is as expected due to the widespread in the dataset for some of the indices in TABLE 2. 
TABLE 3. Influence of yarn spinning method and twist on several FTT fabric indices.

\begin{tabular}{|c|c|c|}
\hline $\begin{array}{c}\text { FTT } \\
\text { Fabric } \\
\text { Indices }\end{array}$ & Model & Adjusted $\mathbf{R}^{2}$ \\
\hline $\mathrm{CW}$ & 2004.47 + 442.58 Ring + 270.85 Compact +268.48 Rotor & 0.433 \\
\hline $\mathrm{T}$ & $1.17+0.51$ Compact +0.40 Ring +0.32 Rotor & 0.539 \\
\hline TCC & $63.89+8.41$ Ring +8.15 Compact +4.65 Rotor & 0.648 \\
\hline TCR & $62.75+8.92$ Compact +8.01 Ring +4.49 Rotor & 0.617 \\
\hline Qmax & $609.62-124.20$ Compact -89.75 Rotor -89.33 Ring & 0.465 \\
\hline BARa & $852.97-\left(0.63 .10^{-3}\right)$ Twist & 0.096 \\
\hline BWa & $1630.59+170.25$ Compact +124.30 Ring $-\left(0.94 .10^{-3}\right)$ Twist & 0.195 \\
\hline RAR & $\begin{array}{l}211.39-72.03 \text { Ring - } 53.19 \text { Compact }-44.94 \text { Rotor }+(0.14 \text {. } \\
\left.10^{-3}\right) \text { Twist }\end{array}$ & 0.429 \\
\hline $\mathrm{SFCa}$ & $0.34+0.03$ Ring $+\left(0.10 .10^{-3}\right)$ Twist +0.01 Rotor +0.01 Compact & 0.489 \\
\hline
\end{tabular}

The models in TABLE 3 indicate that the spinning method has an influence on almost all indices especially in thermal indices i.e., thermal conductivity measured during fabric compression (TCC) and recovery (TCR). Airjet yarns lead to fabrics with the lowest value of $\mathrm{CW}$, T and TCC while ring-spun yarns lead to fabrics with the highest values for CW, based on the results in TABLE 2. Similarly, airjet yarns lead to fabrics with the highest Qmax and surface roughness while ring-spun or compact yarns to the lowest. There is no doubt that the indices within the thermal module i.e., TCC, TCR and Qmax are highly influenced by spinning methods and these indices are included in the comfort models that will be discussed in the further section. The effect of yarn spinning system on fabric properties was also discussed in other studies [25]-[27] that measured single fabric property such as flexural rigidity, compression or drapability using devices like a bending tester, KES-FB2 (pure bending tester), KES-FB3 (compression tester) and drape tester. Similar to these devices, FTT could also distinguish the small variance given by the different types of yarn, with a huge advantage as it is able to measure all the 13 fabric handle properties at once.

The second criterion, twist on the other hand, has positively affected compression and friction properties (RAR and SFC) with the moderate adjusted R2 $\geq 0.40$ (see FIGURE 3). It is also observed that the fabric bending average rigidity (BAR) and bending work (BW) are negatively influenced by twist which means that higher twist makes the fabrics more bendable. However, these models are poor with very low adjusted R2 value. Yarn twist seems not to have influence on the other fabric properties. This however could also be due to the two-level range of twist within a limited range (i.e., 800 and 900 twist/meter). Nonetheless, Matsudaira et al., (2009) also found that the effect of twist is less pronounced on the primary handle of fabrics and that it is also fabric dependent. Overall, the differences in twist cannot be readily linked to the measured changes with the FTT, and hence we need to conclude that the twist change of 800 to 900 twist/meter would not lead to perceptible consistent comfort perception changes, while spinning method does.

\section{Determination of the FTT Comfort Indices}

The comfort indices i.e., smoothness and softness were computed by the FTT software and the results are shown in FIGURE 3. Based on the results, it can be concluded that fabrics with low twisted LT compact yarns are the roughest $(0.02 \pm 0.11)$, airjet-based fabrics are the smoothest $(0.28 \pm 0.08)$ but hardest $(0.61 \pm 0.07)$ and that ring-based fabrics are the softest $(0.70 \pm 0.05)$. Also, fabrics with high twisted yarns HT are smoother than the LT, for the same type of spinning method, except for rotor. However, LT fabrics are softer with the exception of compact yarn. Large variances of the fabric indices can be observed as indicated by the standard deviation bars. However, these results are not yet conclusive, hence further research is needed to verify them using a human panel. 


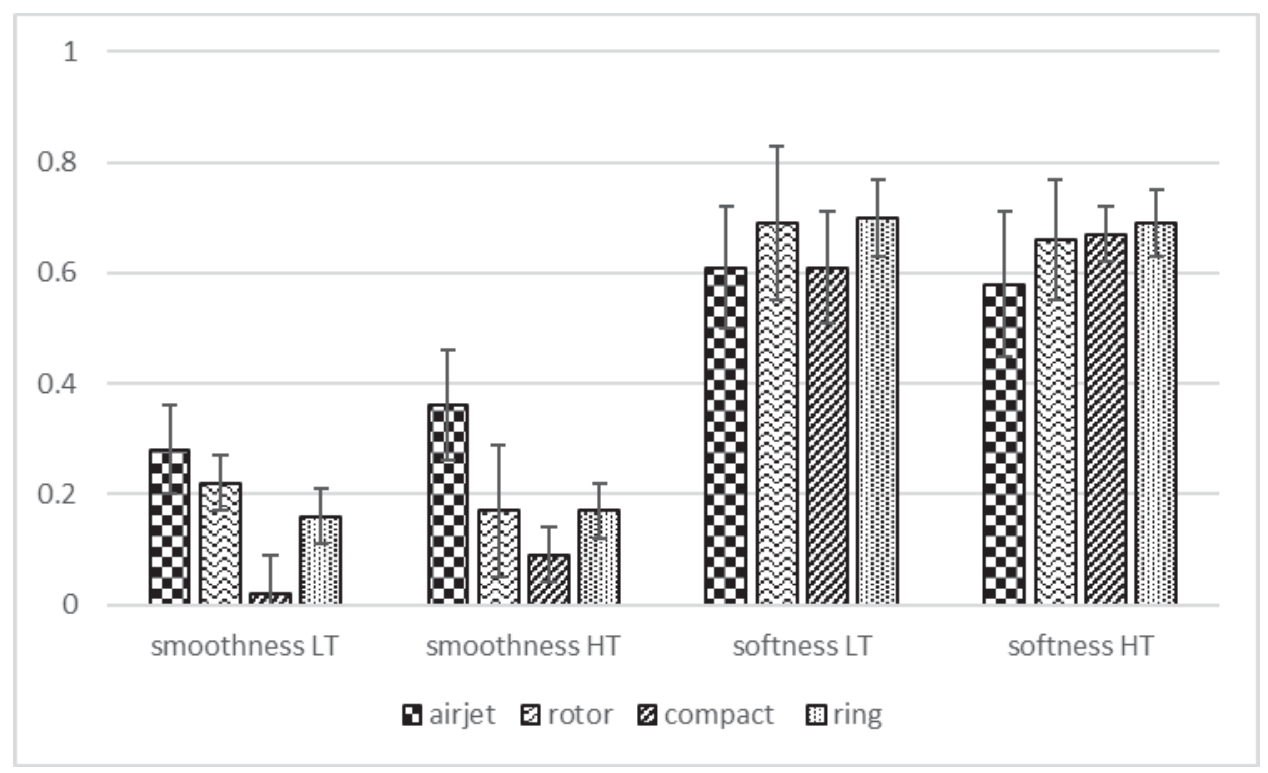

FIGURE 3. FTT- Predicted active smoothness and softness for low twist (LT) and high twist (HT) yarns (p-value $<0.01)$.

\section{CONCLUSION}

Hand properties of eight knitted fabrics with similar structure, differentiated by yarn spinning method (i.e., airjet, rotor, compact and ring spinning) and level of twist were investigated and compared. Several fabric indices were measured by the FTT device and their variation with yarn type and twist was assessed. Comfort indices predicted by the instrument gives huge standard deviation which needs to be further investigated.

FTT device could successfully distinguish between similar fabrics constituted of yarns of four various structures and between the two levels of yarn twist. For the considered fabrics, it was found that the type of yarn has an obvious influence on fabric thermal conductivity while the levels of yarn twist considered moderately affected the compression recovery and surface friction properties of the fabrics.

\section{ACKNOWLEDGEMENT}

The authors acknowledge the scholarship support from the Ministry of Education, Malaysia and Universiti Teknologi MARA, Malaysia for the first author of this paper. The materials were received from Rieter Machine Works Ltd., Switzerland and the results were obtained within an international ERANET-CORNET research project - IWT 140387 (2015-2016) named Touché: Boosting innovation through application of basic understanding of the process and testing of textile touch and fabric feel. The authors also acknowledge the support of Myréne Vanderhoeven in performing part of the tests.

\section{REFERENCES}

[1] A. A. Badr, A. Hassanin, and M. Moursey, "Influence of tencel/cotton blends on knitted fabric performance," Alexandria Eng. J., vol. 55, no. 3, pp. 2439-2447, 2016.

[2] J. Männer, K. C. Schuster, F. Suchomel, A. Gürtler, and H. Firgo, "Higher performance with natural intelligence," Lenzinger Berichte, vol. 83, pp. 99-110, 2004.

[3] B. Özgen and S. Altaş, "The investigation of thermal comfort, moisture management and handle properties of knitted fabrics made of various fibres," Tekst. ve Konfeksiyon, vol. 24, no. 3, pp. 272-278, 2014.

[4] M. Naebe, V. Lutz, B. a. McGregor, D. Tester, and X. Wang, "Effect of surface treatment and knit structure on comfort properties of wool fabrics," J. Text. Inst., vol. 104, no. 6, pp. 600-605, 2013.

[5] H. Morino, M. Matsudaira, and M. Furutani, "Predicting mechanical properties and hand values from the parameters of weave structures," Text. Res. J., vol. 75, no. 3, pp. 252-257, 2005. 
[6] J. O. Kim and B. L. Slaten, "Objective assessment of fabric handle in fabrics treated with flame retardants," J. Test. Eval., vol. 24, no. 4, p. 223, 1996.

[7] V. Sular and A. Okur, "Objective Evaluation of Fabric Handle by Simple Measurement Methods," Text. Res. J., vol. 78, no. 10, pp. 856-868, 2008.

[8] B. K. Behera and P. K. Hari, "Fabric quality evaluation by objective measurement.," Indian J. fibre Text. Res., vol. 19, pp. 168-171, 1994.

[9] S. Kawabata and M. Niwa, "Fabric performance in clothing and clothing manufacture," J. Text. Inst., vol. 80, no. 1, pp. 19-50, 1989.

[10] A. De Boos and D. Tester, "SiroFAST- a system for fabric objective measurement and its application in fabric," Canberra, 1994.

[11] M. Abu-Rous, "Handle properties of fabrics made of wood-based fibers: softness and smoothness of textiles," in 55th Dornbirn Man-Made Fibers Congress (Dornbirn-MFC), 2016.

[12] J. Y. Hu, L. Hes, Y. Li, K. W. Yeung, and B. G. Yao, "Fabric touch tester: integrated evaluation of thermalmechanical sensory properties of polymeric materials," Polym. Test., vol. 25, no. 8, pp. 1081-1090, 2006.

[13] X. Liao, Y. Li, J. Hu, X. Wu, and Q. Li, "A simultaneous measurement method to characterize touch properties of textile materials," Fibers Polym., vol. 15, no. 7, pp. 1548-1559, 2014.

[14] SDL Atlas, "M293 fabric touch tester version 1.0," Shenzhen, 2014.

[15] Touché, "Touché: Boosting innovation through application of basic understanding of the process and testing of textile touch and fabric feel," 2015-2016, 2015. [Online]. Available: http://www.toucheproject.eu/. [Accessed: 23-Aug-2017].

[16] S. Vasile, B. Malengier, A. De Raeve, J. Louwagie, and M. Vanderhoeven, "Assessment of sensorial comfort of fabrics for protective clothing," in 7th European Conference on Protective Clothing ECPC, 2016.

[17] A. Binti Haji Musa, B. Malengier, S. Vasile, L. Van Langenhove, and A. De Raeve, "Analysis and comparison of thickness and bending measurements from fabric touch tester (FTT) and standard methods," Autex Res. J., vol. 18, no. 1, pp. 51-60, 2018.

[18] S. Vasile, B. Malengier, A. De Raeve, and A. Binti Haji Musa, "FTT comfort indices of ring-spun and airjet knitted fabrics with post-treatments," IOP Conf. Ser. Mater. Sci. Eng., vol. 254, no. 18, 2017.

[19] B. K. Behera, S. M. Ishtiaque, and S. Chand, "Comfort properties of fabrics woven from ring-, rotor-, and friction-spun yarns," J. Text. Inst., vol. 88, no. 3, pp. 255-264, 1997.

[20] Y. Suzuki and S. Sukigara, "Mechanical and tactile properties of plain knitted fabrics produced from rayon Vortex yarns," Text. Res. J., vol. 83, no. 7, pp. 740-751, 2012.

[21] P. G. Unal, "Investigation of some handle properties of fabrics woven with two folded yarns of different spinning systems," Text. Res. J., vol. 80, no. 19, pp. 2007-2015, 2010.

[22] ASTM International, "D1776-04: Standard practice for conditioning and testing textiles." ASTM International, West Conshohocken, Pennsylvania, pp. 1-4, 2004.

[23] J. Hu, "Characterization of sensory comfort of apparel products," The Hong Kong Polytechnic University, Hong Kong, 2006.

[24] A. Binti Haji Musa, B. Malengier, S. Vasile, and L. Van Langenhove, "Practical considerations of the FTT device for fabric comfort evaluation," J. Fash. Technol. Text. Eng., vol. S4-003, pp. 1-4, 2018.

[25] M. H. Mohamed and P. R. Lord, "Comparison of physical properties of fabrics woven from open-end and ring spun yarns," Text. Res. J., vol. 43, no. 3, pp. 154-166, 1973.

[26] C. Rameshkumar, P. Anandkumar, P. Senthilnathan, R. Jeevitha, and N. Anbumani, "Comparative studies on ring rotor and vortex yarn knitted fabrics," Autex Res. J., vol. 8, no. 4, pp. 100-105, 2008.

[27] C. D. Kane, U. J. Patil, and P. Sudhakar, "Studies on the influence of knit structure and stitch length on ring and compact yarn single jersey fabric properties," Text. Res. J., vol. 77, no. 8, pp. 572-582, 2007.

[28] M. Matsudaira, K. Nakano, Y. Yamazaki, Y. Hayashi, and O. Hayashi, "Effects of weave density, yarn twist and yarn count on fabric handle of polyester woven fabrics by objective evaluation method," J. Text. Inst., vol. 100, no. 3, pp. 265-274, 2009. 